\title{
Missões na América ibérica: dimensões políticas e religiosas
}

\section{Apresentação}

\author{
Elisa Frühauf Garcia[1]
}

E m 1772, o governador de Buenos Aires comunicou ao governador do Chile uma notícia considerada como "digna de saber-se". Na ocasião, um índio cristão, que conseguira fugir após passar alguns anos como prisioneiro dos índios "infiéis" do Chile, informava sobre a existência de um jesuíta que se tornara cacique. Apesar de não mencionar o nome do inaciano, afirmou que ele tinha oito mulheres e observava rigorosamente todos os costumes vigentes entre "aqueles bárbaros", sendo muito "respeitado e reconhecido." 'Seriam verídicas as informações prestadas pelo índio cristão? Difícil saber. As autoridades coloniais teriam dado mais importância à notícia devido à conjuntura antijesuítica então vigente? Talvez. O caso, porém, indica que semelhante situação era considerada verossímil na sociedade colonial, revelando facetas da experiência missionária ainda abordadas de forma incipiente pela historiografia.

Até recentemente, os estudos sobre as missões reiteravam determinados pressupostos estabelecidos sobre o tema. As interpretações se baseavam em juízos de valor sobre a atividade evangelizadora, sobretudo no caso dos inacianos, e em uma quase absoluta indiferença em relação aos nativos, cujos quereres eram considerados irrelevantes na construção daqueles espaços. Além disso, pouca atenção era dada às especificidades locais e aos consequentes reajustes e negociações característicos da construção da sociedade colonial. ${ }^{2}$

Apesar de a dimensão fronteiriça da atividade missionária ter sido destacada por Herbert Eugene Bolton em um inspirado ensaio publicado em 1917, ela era pouco mencionada por muitos autores, cujas abordagens frequentemente isolavam as 
reduções do contexto mais amplo. ${ }^{3}$ Porém, pela sua condição de estabelecimento fronteiriço, por vezes, verdadeiras pontas de lança da expansão territorial, as missões foram parte indissociável da construção dos impérios ibéricos. Poderiam ser consideradas o "esteio do domínio colonial", como bem definiu Charles Boxer. ${ }^{4}$

Assim, longe de uma dimensão estritamente espiritual, as missões foram parte fundamental do processo de institucionalização do Estado nos domínios americanos. O trabalho dos missionários deveria transformar os índios em súditos leais das monarquias, garantindo, desta forma, a ocupação territorial. Esperava-se também que os novos súditos desempenhassem uma função militar estratégica nos impérios ibéricos: defender as suas fronteiras contra as pretensões expansionistas dos rivais europeus ou dos ataques dos grupos indígenas hostis à presença colonial. Por mais comprometidos que estivessem com a evangelização, os monarcas ibéricos faziam considerações geopolíticas para o financiamento das missões: eram mais generosos quando a concorrência europeia se fazia presente. ${ }^{5}$

\section{Longe de uma dimensão estritamente espiritual, as missões foram parte fundamental do processo de institucionalização do Estado nos domínios americanos}

A associação entre a cruz e a espada, porém, teve uma série de desdobramentos nos estudos sobre as missões. Um deles, ainda objeto de discussões, é o vínculo dos missionários com os seus respectivos padroados e/ou estados de origem. Muitos jesuítas, por exemplo, foram hábeis políticos comprometidos com a construção dos impérios coloniais. No caso português, Antônio Vieira estava tão envolvido nos assuntos da monarquia que, acertadamente, foi denominado por Ronaldo Vainfas como o “jesuíta do rei." ${ }^{6}$ Diante das disputas imperiais, porém, nem todos demonstraram a mesma lealdade. O mesmo Vainfas aborda a trajetória de Manoel de Morais, um jesuíta nascido em São Paulo que atravessou fronteiras políticas e religiosas durante a presença holandesa no nordeste do Brasil. ${ }^{7}$

\footnotetext{
${ }^{3}$ Herbert Eugene Bolton, "La misión como institución de la frontera en el septentrión de Nueva España” [1917], Estudios (Nuevos y Viejos) sobre la frontera, Anexo 4, Revista de Indias, Madri, 1990, CSIC, p. 45-60; David Sweet, "The Ibero-American Frontier Mission in Native American History", In: Erick Langer; Robert Jackson, The New Latin American Mission History, Lincoln, University of Nebraska Press, 1995; Salvador Bernabéu, "La invención del Gran Norte ignaciano: la historiografía sobre la Compañía de Jesús entre dos centenarios (19922006)", In: _ . (coord.), El Gran Norte Mexicano, Sevilla, CSIC, 2009.

${ }^{4}$ Charles Boxer, A Igreja e a Expansão Ibérica (1440-1770), Lisboa, Edições 70, 1989, p. 95.

5Herbert Eugene Bolton, "La misión como institución de la frontera en el septentrión de Nueva España” [1917], Estudios (Nuevos y Viejos) sobre la frontera, Anexo 4, Revista de Indias, Madri, 1990, CSIC, p. 45-60.

${ }^{6}$ Ronaldo Vainfas, Antônio Vieira: jesuíta do rei, São Paulo, Companhia das Letras, 2011. A relação dos jesuítas com o Império português foi bem desenvolvida em: Dauril Alden, The Making of an Enterprise. The Society of Jesus in Portugal, Its Empire, and Beyond, 1540-1750, Stanford, Stanford University Press, 1996.

${ }^{7}$ Ronaldo Vainfas, Traição: um jesuíta a serviço do Brasil holandês processado pela Inquisição, São Paulo, Companhia das Letras, 2008.
} 
O envolvimento dos jesuítas nos mais variados assuntos, temporais e espirituais, na América foi desenvolvido em três artigos deste dossiê. Lígio José de Oliveira Maia analisa a sua participação nos conflitos da Guerra do Açu, um dos episódios do processo de ocupação territorial de parte do nordeste brasileiro no final do século XVII e início do XVIII. Naquele contexto, as alianças respondiam mais às urgentes questões locais do que a determinados princípios pré-estabelecidos pelas ordens religiosas ou à intervenção da Coroa.

As complexas alianças e conflitos nos quais os jesuítas estavam imiscuídos são também analisados por Almir Diniz Carvalho Júnior, com ênfase nas populações nativas. Centrando o artigo nos conflitos entre Antônio Vieira e o Principal indígena Lopo de Souza no Maranhão no século XVII, o autor demonstra os limites e possibilidades da ação dos índios cristãos. Apesar de frequentemente inseridos na sociedade colonial em uma posição desfavorável, os índios eventualmente foram capazes ganhar batalhas travadas contra personagens proeminentes da história colonial, em disputas nas quais a astúcia demonstrada pelos nativos foi um elemento fundamental.

Os reveses da atuação dos missionários são também analisados no artigo de Christophe Giudicelli. Abordando a área andina de Tucumán na segunda metade do século XVII, o autor demonstra a transformação do kakán em "língua do inimigo", à medida que o idioma acabou circunscrito aos índios considerados infensos à sociedade colonial. De tal processo, surgiu um dilema para os jesuítas: após um grande investimento para aprendê-lo com fins evangelizadores, acabaram atuando como intérpretes nas tropas enviadas contra os índios.

Os artigos deste dossiê destacam ainda as ações dos índios, hoje consideradas imprescindíveis para a compreensão das atividades missionárias. Pesquisas sobre diferentes regiões da América têm demonstrado o papel ativo das populações nativas, revelando situações concretas nas quais, em detrimento de impor seus pontos de vista, os jesuítas foram hábeis negociadores, gerando ajustes políticos e religiosos muitas vezes distantes do convencional. ${ }^{8}$ Em certas ocasiões, o fizeram por gosto, como no caso dos que se identificavam demasiado com os índios e geravam situações embaraçosas para a Companhia. Apesar de pouco divulgado pelos inacianos, cujo interesse era propagar a sua própria habilidade de conversão, as populações nativas possuíam uma capacidade de convencimento nada desprezível, como parece ter acontecido no caso do Chile narrado acima.

Ao aprofundar o diálogo com a história dos índios, as análises sobre a experiência missionária colocaram em questão as diversas dimensões da religião católica no processo de reorganização ou criação das comunidades indígenas na América. Até recentemente, na historiografia brasileira, predominava uma perspectiva fatalista do contato dos índios com o catolicismo. Especialmente devido à influência do trabalho de Luiz Felipe Baeta Neves, para quem a "Aldeia não é mais um espaço indígena. É um espaço criado pela cultura cristã." ${ }^{9} \mathrm{Em}$ tal

8Sobre as reformulações do projeto missionário dos jesuítas no Brasil, veja-se: Charlotte de Castelnau-L'Estoile, Operários de uma vinha estéril: os jesuítas e a conversão dos índios no Brasil, 1580-1620. Bauru, Edusc, 2006. 'Luiz Felipe Baeta Neves, O combate dos soldados de Cristo na terra dos papagaios, Rio de Janeiro, Forense Universitária, 1978, p. 117 (grifos no original). 
perspectiva, as opções dos índios eram limitadas. Ou fugiam da sociedade colonial e mantinham a sua "religiosidade tradicional" ou se convertiam ao catolicismo, considerada como uma etapa fundamental do seu aniquilamento cultural pelo "colonialismo" português. Os matizes apresentados pela historiografia sobre a história dos índios foram fundamentais para a mudança desse panorama. Afinal, como assinalou James Lockhardt, "ninguna de las dos categorías, la conversión o la resistencia, nos dice toda la verdad." 10

A religião adquiriu diversos significados na história dos contatos: poderia ser utilizada como uma estratégia de convencimento pelos europeus de diferentes confissões e que acabavam envolvendo os índios nas suas disputas religiosas e territoriais. ${ }^{11}$ Foi ainda apresentada pelos próprios índios como um benefício trazido pelos espanhóis, em uma estratégia por meio da qual eles enfatizavam a conversão, em detrimento da conquista militar, para marcar o seu ingresso no mundo colonial, como demonstrou Serge Gruzinski. ${ }^{12}$ De uma maneira geral, pode-se pensar que os significados dos aldeamentos foram construídos e negociados pela população nativa, como analisou Maria Regina Celestino de Almeida para o caso do Rio de Janeiro. ${ }^{13} \mathrm{O}$ contrário, porém, também ocorreu: em revoltas indígenas contra a sociedade colonial, o catolicismo foi apresentado como um símbolo da dominação ibérica. ${ }^{14}$

\section{Até recentemente, na historiografia brasileira, predominava uma perspectiva fatalista do contato dos índios com o catolicismo}

Assim, ao considerar a negociação como um elemento indissociável da experiência missionária, os estudos demonstram como a religiosidade surgida nesses espaços estava muito além de uma mera imposição do catolicismo: vinculava-se, necessariamente, às percepções e aos quereres dos nativos. ${ }^{15} \mathrm{Tal}$ aspecto foi desenvolvido neste dossiê por Charlotte de Castelnau-L'Estoile. A partir dos diálogos entre as lideranças indígenas e os capuchinos envolvidos

\footnotetext{
10 James Lockhardt, Los nahuas después de la conquista: historia social y cultural de los indios del México central, del siglo XVI al XVIII, México, Fondo de Cultura Económica, 1999, p. 291.

"James Axtell, The invasion within: the contest of cultures in Colonial North America, New York, Oxford University Press, 1985; Mark Meuwese, Brothers in arms, partners in trade: Dutch-indigenous alliances in the Atlantic world, 1595-1674, Leiden; Boston, Brill, 2012

12Serge Gruzinski, A colonização do imaginário: sociedades indígenas e ocidentalização no México espanhol. Séculos XVI-XVIII, São Paulo, Companhia das Letras, 2003.

${ }^{13}$ Maria Regina Celestino de Almeida, Metamorfoses indígenas: identidade e cultura nas aldeias coloniais do Rio de Janeiro, Rio de Janeiro, Arquivo Nacional, 2003.

${ }^{14}$ Steve Stern, Los pueblos indígenas del Perú y el desafío de la conquista española-Huamanga hasta 1640, Madri, Alianza, 1986; Ronaldo Vainfas, A heresia dos indios: catolicismo e rebeldia no Brasil colonial, São Paulo, Companhia das Letras, 1995.

${ }^{15}$ Cristina Pompa, Religião como tradução: missionários, Tupi e Tapuia no Brasil colonial, Bauru, SP, Edusc, 2003; Paula Montero (org.), Deus na aldeia: missionários, índios e mediação cultural, São Paulo, Globo, 2006; Cynthia Radding, Paisajes de poder e identidad: fronteras imperiales en el desierto de Sonora y bosques de la Amazonía, Sucre, Fundación Cultural del Banco Central de Bolivia; Archivo y Biblioteca Nacionales de Bolivia, 2005.
} 
na experiência da França equinocial no início do século XVII, a autora demonstra as negociações presentes nos contatos interétnicos. Problematizando as fontes produzidas pelos missionários, evidencia como elas foram fruto de um diálogo que tentava conciliar, com sucesso variado, os diversos interesses que moviam os sujeitos naquele contexto histórico.

Da articulação do catolicismo com o estabelecimento da sociedade colonial, também surgiram importantes trabalhos, cujas questões são fundamentais para a compreensão das relações de poder constituintes dos espaços missionários. Ainda que a utilização da religião como um elemento de hierarquização e de exclusão já estivesse presente em trabalhos que podem ser considerados clássicos sobre a evangelização, como o de Robert Ricard, a problemática tem favorecido abordagens instigantes e é ainda um campo propício para novos trabalhos. ${ }^{16}$ Afinal, qual foi o papel da religião na manutenção dos índios em condição subordinada aos ibéricos na América colonial?

Tal questão, evidentemente, não possui uma resposta única: as situações variavam conforme o tempo, as regiões e a habilidade dos sujeitos envolvidos em situações concretas. ${ }^{17} \mathrm{Um}$ dos temas fundamentais para relacionar o lugar do catolicismo, e da atividade missionária, à construção dos significados coloniais do termo "índio" são os debates sobre a conveniência do ingresso dos nativos no sacerdócio. O tema agitou a sociedade colonial, especialmente no México e no Peru. ${ }^{18}$

Em linhas gerais, porém, pode-se afirmar que a condição de neófitos excluía os índios do exercício de uma série de atividades. Como destacaram alguns autores, dentre eles Juan Carlos Estenssoro, a conversão ao catolicismo desencadeava uma situação na qual os índios se viam destituídos de autonomia no campo religioso, pois dependiam dos sacerdotes de origem europeia para satisfazerem as suas necessidades espirituais. ${ }^{19}$ A questão, como assinalado acima, no entanto, é repleta de matizes. Em muitos casos, o controle exercido pelos párocos ou missionários nas comunidades indígenas era consideravelmente

\footnotetext{
${ }^{16}$ Robert Ricard, La conquista espiritual de México, México, Fondo de Cultura Económica, 1986 [1947]. O tema também foi desenvolvido por Charles Boxer, A Igreja e a Expansão Ibérica (1440-1770), Lisboa, Edições 70, 1989. ${ }^{17 P a r a}$ uma relação entre a condição indígena e a construção de uma sociedade de Antigo Regime na América colonial, veja-se: Karen Spalding, “¿Quiénes son los indios?", In: __... De indio a campesino, Lima, Instituto de Estudios Peruanos, 1974, p. 147-193; Jacques Poloni-Simard, "Historia de los indios en los Andes, los indígenas en la historiografía andina: análisis y propuestas". Mundo Nuevo Nuevos Mundos, revista eletrônica, Paris, 2011. Disponível em: <www.nuevomundo.revues.org/651.htm>. Acesso em: 16 de junho de 2012.

${ }^{18}$ Robert Ricard, La conquista espiritual de México, México, Fondo de Cultura Económica, 1986 [1947]; Ignacio Osorio Romero, La enseñanza del latín a los indios, México, D.F., Universidad Nacional Autónoma de México, 1990; Margarita Menegus Bornemann; Rodolfo Aguirre, Los indios, el sacerdocio y la Universidad en Nueva España, siglos XVI-XVIII, México, Universidad Nacional Autónoma de México, 2006; Monique AlaperrineBouyer, La educación de las elites indígenas en el Perú colonial, Lima, Instituto Francés de Estudios Peruanos; Instituto Riva-Agüero; Instituto de Estudios Peruanos, 2007; Pilar Gonzalbo Aizpuru, Historia de la educación en la época colonial: el mundo indígena. México, El Colegio de México, Centro de Estudios Históricos, 2000. ${ }^{19}$ Juan Carlos Estenssoro, Del paganismo a la santidad: la incorporación de los indios del Perú al catolicismo, 1532-1750, Lima, Instituto Francés de Estudios Andinos, 2003. Tal panorama começou a se modificar durante as reformas ibéricas da segunda metade do século XVIII, quando as promessas de igualdade jurídica aos índios incluíam o incentivo ao exercício do sacerdócio, inclusive para os índios das regiões de fronteira. Sobre o tema, veja-se: David Weber, Bárbaros: los españoles y sus salvajes en la era de la llustración, Barcelona, Crítica, 2007, especialmente o capítulo 3, "La ciencia de criar hombres", p. 139-205.
} 
restrito (e os motivos variavam: não dominavam o idioma, não tinham interesse, eram em número muito reduzido, entre outros).$^{20}$

$\mathrm{O}$ artigo de Elisa Frühauf Garcia aborda a questão do estatuto dos índios na sociedade colonial a partir do caso das missões do Paraguai no século XVIII. Mais do que evidenciar o funcionamento de tal estatuto, a autora busca demonstrar como os próprios índios percebiam a sua condição jurídica diferenciada, sobretudo quando ela se apresentava como um entrave para as suas expectativas de realização pessoal.

Assim, este dossiê reúne artigos de pesquisadores que se dedicaram a analisar a questão das missões considerando algumas das variáveis já destacadas por alguns autores, como mencionado acima, mas postas em segundo plano pela historiografia em um dado momento. As disputas que envolviam os espaços missionários, as incertezas características das áreas fronteiriças, a pouca operacionalidade das categorias dicotômicas e a indissociabilidade entre os contatos religiosos e o estabelecimento do poder colonial são aspectos desenvolvidos pelos autores convidados. Boa leitura!

20Sobre o tema, veja-se, por exemplo, James Lockhardt, Los nahuas después de la conquista: historia social y cultural de los indios del México central, del siglo XVI al XVIII, México, Fondo de Cultura Económica, 1999. 